\title{
SMART SUSTAINABLE CITY FRAMEWORK: USULAN MODEL KOTA CERDAS YANG BERKELANJUTAN DAN INTEGRATIF
}

\section{SMART SUSTAINABLE CITY FRAMEWORK: THE SUSTAINABLE AND INTEGRATIVE SMART CITY PROPOSED MODEL}

\author{
Inasari Widiyastuti ${ }^{1}$, Daru Nupikso ${ }^{2}$, Novian Anata Putra ${ }^{3}$, Vieka Aprilya Intanny ${ }^{4}$ \\ 1,2,3,4 Balai Pengembangan SDM dan Penelitian (BPSDMP) Kominfo Yogyakarta \\ ${ }^{1}$ inas001@ kominfo.go.id, ${ }^{2}$ daru001@ kominfo.go.id, ${ }^{3}$ novi010@kominfo.go.id, ${ }^{4}$ viek001@kominfo.go.id
}

Diterima: 20 Juli 2020

Direvisi: 11 Agustus 2020

Disetujui: 03 September 2020

\begin{abstract}
The existing smart city model has been able to identify dimensions and enabler components. This makes the smart city implementation work, but it is unable to measure the maturity and prepare a strategy for the city. Regional characteristics has become prerequisite for the implementation of a model that refers to large cities with established infrastructure. Many cities and regencies have taken the initiative to realize smart city but there is no comprehensive self-evaluation model available to measure the level of maturity. The aim of this research is to create a model and indicators of integrated smart city in accordance with the characteristics of cities and districts in Indonesia. The Smart Sustainable City Framework (SSCF) model is a self-measuring model of the maturity level of the smart city enabler components, the priority level of the smart city dimensions, and the level of availability of indicator data that can be used by local governments. The SSCF model consists of enabler components dan dimensions. The enabler component is a core component that is driven by local governments, including governance and technology. While the dimensions include smart mobility, smart governance, smart environment, smart living, smart people, and smart economy. With these measurements, it is hoped that local governments will have a comprehensive description and measurement results at the time of measurement to formulate a strategy for implementing smart city in their regions.
\end{abstract}

Keywords: Smart Sustainable City, Enabler Component, Smart City Dimensions, Smart City Indicators, Local Government

\section{ABSTRAK}

Model smart city yang tersedia telah mampu mengidentifikasi dimensi dan komponen enabler yang menjadikan implementasi berjalan tetapi belum cukup untuk mengukur kematangan dan menyiapkan strategi. Karakteristik daerah turut menjadi prasyarat implementasi model yang mengacu pada kota-kota besar dengan infrastruktur yang telah mapan. Banyak kota dan kabupaten yang berinisiatif mewujudkan smart city tetapi belum tersedia model evaluasi diri yang komprehensif untuk mengukur tingkat kematangannya. Penelitian ini bertujuan untuk membuat model dan indikator smart city yang terintegrasi sesuai dengan karakteristik kota dan kabupaten di Indonesia. Model Smart Sustainable City Framework (SSCF) merupakan model pengukuran diri terhadap tingkat kematangan komponen enabler smart city, tingkat prioritas dimensi smart city, dan tingkat ketersediaan data indikator yang dapat digunakan oleh pemerintah daerah. Model SSCF terdiri dari layer komponen enabler dan dimensi SSCF. Komponen enabler adalah komponen inti yang digerakkan oleh pemerintah daerah dan meliputi tata kelola dan teknologi. Adapun komponen dimensi meliputi smart mobility, smart governance, smart environment, smart living, smart people, dan smart economy. Dengan pengukuran tersebut, diharapkan pemerintah daerah memiliki deskripsi dan hasil pengukuran yang komprehensif pada kondisi saat pengukuran untuk menyusun strategi implementasi smart city di daerahnya.

Kata Kunci: Smart Sustainable City, Komponen Enabler, Dimensi Smart City, Indikator Smart City, Pemerintah Daerah 


\section{PENDAHULUAN}

Kota sebagai pusat peradaban manusia tidak dapat dipisahkan dari permasalahan akibat kapasitas berlebih dan tuntutan akan kenyamanan hidup (Purnomo \& Prabowo, 2016). Pertumbuhan populasi, perubahan kekuatan ekonomi, dan perkembangan teknologi adalah konsekuensi dari kapasitas berlebih yang menjadi tantangan perkotaan, selain adanya kompetisi antarkota yang memengaruhi daya saing kota (Giffinger \& Gudrun, 2010). Bagi banyak pihak, pesatnya pertumbuhan populasi perkotaan akibat urbanisasi adalah faktor yang kerap diisukan sebagai pemicu permasalahan urban (Anindra, Supangkat, \& Kosala, 2018; Hara, Nagao, Hannoe, \& Nakamura, 2016; Nam \& Pardo, 2011a; Yudatama, n.d.). Populasi yang tinggi menuntut kebutuhan akan infrastruktur, transportasi, dan lingkungan yang berkualitas serta stabilitas ekonomi. Tantangan yang dihadapi kota berbeda-beda tergantung pada sejarah, budaya, dan lingkungannya (Hara et al., 2016). Bagi kota-kota di Eropa, meski menjadi temuan, pertumbuhan populasi tidak menjadi isu utama sebagai pemicu permasalahan kota. Tantangan terhadap isu lingkungan, perubahan iklim, penggunaan energi terbarukan, dan daya saing justru menjadi perhatian serius. Untuk mencapai kehidupan yang layak bagi warganya secara berkelanjutan, baik di masa kini dan mendatang, kota memerlukan solusi cerdas dan inovatif.

Smart city atau kota cerdas menjadi tren sebagai solusi masalah perkotaan secara inovatif. Menurut Nam \& Pardo (2011b), smart city adalah kota yang mampu mengidentifikasi masalah sejak dini berdasarkan data yang dimiliki untuk membuat keputusan yang lebih baik dalam proses pencegahan, penanggulangan, dan pembangunan dengan kolaborasi pada setiap entitas dan domain. Smart city memfasilitasi masuknya informasi ke dalam infrastruktur fisik melalui beragam aplikasi sehingga kota mengetahui kebutuhan riil masyarakat secara dini agar dapat meningkatkan kualitas hidup, membuat operasi dan layanan perkotaan berjalan efisien, serta memastikan terpenuhinya kebutuhan generasi mendatang (UNECE \& ITU, n.d.; Yudatama, n.d.). Smart city diharapkan dapat meningkatkan kualitas dan kenyamanan hidup masyarakat serta memastikan terpenuhinya kebutuhan tiap generasi dalam berbagai sektor (Hara et al., 2016; ISO/IEC, 2014; Nam \& Pardo, 2011b; UNECE \& ITU, n.d.). Konsep smart city ini kerap dikaitkan dengan penggunaan teknologi untuk membangun dan mengintegrasikan infrastruktur dan layanan sebagai solusi inovatif (Nam \& Pardo, 2011b, 2011a; Yudatama, n.d.) guna mengidentifikasi masalah dan memperbaikinya segera secara efektif dan efisien (Nam \& Pardo, 2011b).

Masifnya konsep smart city yang berkorelasi dengan teknologi tidak dapat dipersalahkan karena Boyd Cohen menyebutkan generasi pertama dari smart city (Smart City 1.0) adalah technology driven (Cohen, 2015a), yaitu implementasi smart city yang didorong oleh penggunaan teknologi informasi. Faktanya, ada 3 (tiga) faktor pengungkit smart city, yakni tata kelola organisasi dan institusi, sumber daya manusia, dan teknologi (Chourabi et al., 2012; GilGarcia, Pardo, \& Nam, 2015; Nam \& Pardo, 2011b; Supangkat \& Arman, 2018). Jika ketiga enabler ini dipenuhi maka kolaborasi setiap entitas smart city dapat terlaksana sehingga Smart City 3.0 dengan citizen cocreation-nya dapat tercapai (Cohen, 2015a).

Meski belum ada definisi dan konsep yang disepakati bersama, terdapat beberapa 
model yang berkembang dan diacu banyak kota seperti model Giffinger (Giffinger, 2007; Giffinger \& Gudrun, 2010) dan model Cohen (Cohen, 2015b). Adapun di Indonesia, berkembang model Citiasia (Citiasia Center for Smart Nation, 2016) yang diacu Kementerian Komunikasi dan Informatika serta model Garuda atau Garuda Smart City Framework (GSCF) (Supangkat, Arman, Nugraha, \& Fatimah, 2018). Sebagian besar model menempatkan indikator smart city sebagai acuan pelaksanaan dan pencapaian.

Model Giffinger dirujuk oleh banyak pihak karena akurasinya dalam membidik isu sentral smart city dalam rumusan indikator capaian yang komprehensif. Terdapat 74 indikator yang 65\% di antaranya didefinisikan pada tingkat daerah (Giffinger, 2007; Giffinger \& Gudrun, 2010). Sayangnya, model Giffinger hanya berlaku pada kota berskala medium sesuai karakteristik kota-kota di Eropa dengan jumlah populasi 100.000 - 500.000. Adapun Cohen menawarkan konsep kota pintar yang berkelanjutan (sustainable city) yang 62 indikatornya hanya dapat diimplementasikan jika terjadi kolaborasi yang masif di antara seluruh penghuni kota (Cohen, 2015a, 2015b). Baik Giffinger maupun Cohen, merepresentasikan smart city dalam 6 (enam) dimensi yaitu smart economy, smart people, smart governance, smart mobility, smart environment, dan smart living. Dalam rumusan indikator, keduanya memasukkan indikatorindikator yang bersumber dari seluruh entitas perkotaan, tidak hanya indikator yang menjadi domain pemerintah.

Dalam konteks Indonesia, GSCF telah mengklasifikasi kota berdasarkan populasi yang sesuai dengan kondisi Indonesia, yaitu berpenduduk 200.000 hingga 1 juta jiwa (Anindra et al., 2018; Supangkat \& Arman, 2018). Meski menggunakan 6 (enam) dimensi yang sama dengan model Giffinger dan model Cohen, GSCF menambahkan proses pengukuran kesiapan dalam modelnya untuk mengidentifikasi posisi kota sehingga dapat meningkatkan kesiapan adopsi smart city. Ini berbeda dengan model Citiasia yang meski mengidentifikasi 6 (enam) dimensi, memiliki perbedaan dimensi dan indikator dengan model lainnya. Model Citiasia memasukkan dimensi branding untuk mempromosikan nilai sebuah kota dan menempatkan dimensi mobility sebagai bagian dari area kerja dimensi living. Di dalam model lainnya, dimensi branding menjadi area kerja dan/atau indikator di dimensi economy. Model Citiasia juga tidak menjelaskan karakteristik populasi atau daerah yang sesuai dengan konteks model meskipun dapat digunakan unuk mengukur kesiapan (readiness) (Citiasia Center for Smart Nation, 2016).

Konteks model yang ada, khususnya model dari kota-kota di Eropa, mengacu pada kota maju yang telah mapan dari sisi infrastruktur, politik, kebijakan, ekonomi, dan pendidikan. Terbatasnya sumber daya alam, semangat mengoptimalkan energi terbarukan, upaya mewujudkan kota layak huni berkelanjutan, serta proses pemanfaatan teknologi informasi dan komunikasi menjadi latar belakang munculnya konsep smart city (Giffinger \& Gudrun, 2010; Lazaroiu \& Roscia, 2012). Kondisi tersebut berbeda dengan di Indonesia yang memulainya dari tren penggunaan teknologi, khususnya dalam pelayanan publik dan pemerintahan atau dikenal dengan e-government. Tren smart city yang berkembang di Indonesia dilatarbelakangi oleh pertumbuhan populasi akibat urbanisasi yang menjadi isu utama, meski belum terbukti kebenarannya dan masih berupa peramalan. Namun, kebijakan untuk mewujudkan kota layak huni, aman, dan 
nyaman pada tahun 2025 serta kota cerdas yang berkelanjutan dan berdaya saing berbasis teknologi pada tahun 2045 telah ditetapkan oleh BAPPENAS (BAPPENAS, 2015). Kemkominfo pun turut menggalakkan Gerakan 100 Smart City sejak 2017 yang melibatkan kabupaten dan kota dengan salah satu faktor penentunya adalah kecukupan nilai PAD atau Pendapatan Asli Daerah dan Anggaran Pendapatan dan Belanja Daerah (APBD). Sejumlah indikator digunakan untuk menilai capaian smart city.

Model yang digunakan, seperti GSCF dan Citiasia, menempatkan kota/kabupaten pada posisi awal yang sama, kemudian dilakukan pemeringkatan capaian berdasarkan luas wilayah dan/atau jumlah populasi. Meski pemeringkatan perlu, terlebih Indonesia senang pada ekosistem kompetitif, menyamaratakan kota/kabupaten tidaklah sesuai karena karakteristik dan faktor pengungkit yang berbeda. Selain itu, konsep smart city mengacu pada perkotaan sedangkan Indonesia memiliki ketentuan wilayah administrasi dari tingkat pusat, provinsi, kota, kabupaten, hingga desa dengan kebijakannya masing-masing. Di sisi lain, wilayah kabupaten tidak mengalami isu krusial terkait populasi, memiliki cakupan yang luas, dan infrastruktur yang belum mapan. Akan tetapi, konteks smart city yang merujuk pada karakteristik perkotaan banyak diacu oleh kabupaten dengan karakteristik yang berbeda. Kota-kota berukuran sedang dan kabupaten harus menghadapi tantangan kota besar dan diposisikan sama dalam keunggulan kompetitif serta sumber daya padahal mereka berbeda dalam isu-isu kritis, sumber daya, dan tata kelola.

Sementara itu, model yang berkembang saat ini tidak sedikit yang dikritisi karena indikator smart city kurang mencerminkan kondisi realitas inovasi perkotaan, tidak efektif, dan tidak mempertimbangkan jenis kota (Anthopoulos \& Janssen, 2015). Perspektif menyimpangkan dapat terjadi ketika mengganggap smart city dapat diukur dengan satu alat ukur (Lazaroiu \& Roscia, 2012) serta model yang sama untuk kota dengan karakteristik berbeda (Anthopoulos \& Janssen, 2015). Sebuah kota bisa jadi baik berdasarkan model tertentu tetapi tidak pada model yang lain. Ada kodifikasi kategori yang sangat dekat dengan kebijakan. Identifikasi indikator terhadap ruang dan waktu dari referensi sangat diperlukan. Selain itu, model smart city berfokus pada capaian indikator dan mengabaikan dimensi enabler sebagai input dari ketercapaian.

Walaupun demikian, model smart city yang berkembang telah mampu mengidentifikasi dimensi dan komponen enabler yang menjadikan implementasinya berjalan sukses. Meski demikian, konteks dan indikator yang digunakan dalam model belum sesuai dengan karakteristik kota/kabupaten di Indonesia. Penelitian ini bertujuan membuat kerangka kerja model dan indikator smart city yang sesuai dengan karakteristik kota/kabupaten di Indonesia. Penelitian ini merupakan bagian dari kegiatan penelitian yang dilaksanakan oleh BPSDMP Kominfo Yogyakarta pada tahun 2019 dengan judul "Smart Sustainable City: Usulan Model Kota Cerdas yang Berkelanjutan dan Integratif" (BPSDMP Kominfo Yogyakarta, 2019). Tulisan ini hanya membahas proses perumusan model Smart Sustainable City, sedangkan proses pengujian tidak dibahas.

\section{METODOLOGI PENELITIAN}

Penelitian ini merupakan penelitian eksploratif karena mengkaji pengetahuan secara lebih mendalam dan mencari ide-ide 
baru mengenai suatu gejala dan menjelaskan bagaimana suatu temuan (fenomena) dapat terjadi untuk mengembangkan hipotesis atau model yang telah ada (Mudjiyanto, 2018). Penelitian eksploratif merupakan kombinasi antara penelitian deskriptif dan penelitian eksperimen tetapi tidak dapat diartikan secara mandiri (Mudjiyanto, 2018). Dengan kombinasi ini, temuan pada kerangka kerja Smart Sustainable City ini diharapkan akan komprehensif karena mengembangkan hipotesis atau model yang telah ada sesuai dengan konteks kota dan kabupaten di Indonesia.

Kerangka kerja atau framework merupakan bagian dari penelitian eksploratif yang menganalisis data kualitatif yang diterapkan dalam penelitian kebijakan. Pendekatan kerangka kerja diterapkan dalam penelitian ini karena lebih cocok untuk menganalisis data deskriptif yang bersifat cross-sectional terhadap berbagai aspek yang muncul pada fenomena yang diinvestigasi (Smith \& Firth, 2011). Penelitian ini akan menghasilkan kerangka kerja Smart Sustainable City. Mengacu pada model yang berkembang dan untuk menyesuaikan dengan konteks karakteristik kota dan kabupaten, kerangka kerja Smart Sustainable City diturunkan menjadi komponen enabler, dimensi, dan indikator.

Komponen enabler adalah pilar dari komponen smart city yang meliputi tata kelola, sumber daya manusia, dan teknologi. Komponen enabler menjadi input atau kondisi yang diperlukan bagi suksesnya implementasi smart city secara berkelanjutan. Tingkat kematangan kondisi saat ini dari tiap komponen enabler pemerintah daerah perlu ditinjau untuk menilai kekuatan dan kelemahannya sehingga dapat dirumuskan strategi implementasi yang tepat. Komponen enabler meliputi area kerja dan indikatorindikator yang harus terpenuhi. Sementara itu, komponen dimensi merupakan sektor kinerja pemerintah daerah yang dikelompokkan secara luas dalam 6 (enam) hal, yaitu smart mobility, smart governance, smart environment, smart living, smart people, dan smart economy. Setiap dimensi mencakup beberapa area kerja. Dimensi dan area kerja ini secara lebih detil dirumuskan dalam indikator-indikator capaian smart city. Dimensi, area kerja, dan indikator merupakan output dan outcome dari proses implementasi smart city secara berkelanjutan.

Penelitian ini merumuskan kerangka kerja smart sustainable city secara komprehensif pada sisi input sebagai sebuah proses menuju smart city dan sisi keluaran sebagai capaian indikator smart city secara berkelanjutan. Pengukuran terhadap kriteria input dan kriteria output penting dilakukan untuk mengetahui secara jelas tentang area mana yang perlu mendapat fokus perhatian dari kota dan kabupaten agar dapat mencapai output yang diharapkan (Anand, Winfred Rufuss, Rajkumar, \& Suganthi, 2017). Model yang berkembang saat ini menempatkan kota pada sisi input yang sama sedangkan isu yang dihadapi tiap kota berbeda-beda. Proses perumusan dilakukan dengan cara meninjau model-model smart city yang berkembang yaitu model Giffinger (Giffinger, 2007; Giffinger \& Gudrun, 2010), Model Smart City Wheel (Cohen, 2015b, 2015a), model Garuda Smart City Framework (Anindra et al., 2018; Supangkat et al., 2018), model Citiasia Smart Nation (Citiasia Center for Smart Nation, 2016), dan Smart Sustainable City Indicator ITU-UNECE (UNECE \& ITU, n.d.) seperti ditunjukkan pada Tabel 1. Tabel 1 memperlihatkan model-model smart city serta peraturan dan standar yang dijadikan rujukan. Tinjauan ini kemudian dieksplorasi dengan 
konteks Indonesia, mengacu pada peraturan yang berlaku.

Observasi dan wawancara dengan pemerintah daerah dilakukan untuk meninjau ulang rumusan agar perbedaan karakteristik dapat dijembatani sehingga setiap kota dan kabupaten dapat menggunakan model ini tanpa kendala. Pemerintah daerah yang terlibat dalam peninjauan adalah Kota Jogja, Kabupaten Sleman, Kota Semarang, Kabupaten Boyolali, Kota Denpasar, dan Kabupaten Badung. Pemilihan kota dan kabupaten ini didasari oleh partisipasi pada Gerakan 100 Smart City tahun 2017 dan 2018 dan paparan Menteri Komunikasi dan Informatika tentang faktor PAD yang berpengaruh terhadap implementasi smart city. Dari 100 kota dan kabupaten tersebut, peneliti memilih kota dan kabupaten dengan PAD tertinggi untuk wilayah Jawa Tengah, DI Yogyakarta, dan Bali. Kota dan kabupaten memiliki karakteristik berbeda sehingga keduanya perlu diteliti untuk menilai berfungsi dengan baik atau tidaknya kerangka kerja.

Tabel 1. Model-Model Smart City yang Diadopsi

\begin{tabular}{|c|c|c|}
\hline $\begin{array}{l}\text { Level Peninjauan } \\
\text { (Komponen/Dimensi/Indikator) }\end{array}$ & $\begin{array}{l}\text { Tinjauan } \\
\text { Model/Regulasi/Standar }\end{array}$ & Sumber Rujukan \\
\hline \multirow[t]{3}{*}{$\begin{array}{l}\text { Komponen dan Faktor Pendorong } \\
\text { Smart City }\end{array}$} & $\begin{array}{l}\text { Conceptualizing Smart City } \\
\text { Components }\end{array}$ & (Nam \& Pardo, 2011a, 2011b) \\
\hline & $\begin{array}{l}\text { An Integrative Framework of } \\
\text { Smart City }\end{array}$ & (Chourabi et al., 2012) \\
\hline & Smart City Maturity Model & (Urban Tide, 2014) \\
\hline \multirow[t]{6}{*}{ Dimensi dan Indikator Smart City } & Model Smart City Giffinger & $\begin{array}{l}\text { (Giffinger, 2007; Giffinger \& } \\
\text { Gudrun, 2010) }\end{array}$ \\
\hline & $\begin{array}{l}\text { Model Smart City Wheel } \\
\text { Cohen }\end{array}$ & (Cohen, 2015b) \\
\hline & $\begin{array}{lll}\text { Garuda } & \text { Smart } & \text { City } \\
\text { Framework } & & \end{array}$ & $\begin{array}{l}\text { (Anindra et al., 2018; Supangkat } \\
\text { \& Arman, 2018; Supangkat et } \\
\text { al., 2018) }\end{array}$ \\
\hline & Citiasia Smartnation & $\begin{array}{l}\text { (Citiasia Center for Smart } \\
\text { Nation, 2016) }\end{array}$ \\
\hline & $\begin{array}{lll}\text { Smart } & \text { Sustainable } & \text { City } \\
\text { Indicator } & \text { UNECE-ITU } & \end{array}$ & (UNECE \& ITU, n.d.) \\
\hline & $\begin{array}{l}\text { Sustainable } \\
\text { Goals (SDGs) }\end{array}$ & \\
\hline
\end{tabular}

\section{HASIL DAN PEMBAHASAN}

Kerangka kerja Smart Sustainable City Framework (SSCF) dikembangkan oleh peneliti BPSDMP Kominfo Yogyakarta dengan mengadopsi beberapa model yang berkembang serta menyesuaikannya dengan konteks Indonesia. Pengembangan kerangka kerja dilakukan pada tahun 2018 dan 2019. Proses penyesuaian dilakukan dengan observasi dan pengujian pada kota dan kabupaten yang melaksanakan Gerakan 100
Smart City sehingga diperoleh kerangka kerja yang dapat digunakan oleh kota dan kabupaten mana pun. Penyesuaian utama terletak pada sinkronisasi area kerja dan indikator yang harus dipenuhi oleh kota dan kabupaten mengacu pada Sustainable Development Goals (SDGs), RPJMN, dan RPJMD. Sinkronisasi ini penting dilakukan agar kinerja daerah tidak terhambat karena perbedaan target sasaran dan nomenklatur yang dikeluarkan oleh banyak instansi sedangkan tujuan yang akan dicapai 
adalah sama. Perbedaan ini menjadi concern pemerintah kota dan kabupaten. Selain mengendurkan performa pemerintah daerah, perbedaan nomenklatur akan menghambat proses integrasi data untuk mencapai Indonesia Satu Data. Bagian utama dari terlaksananya smart city adalah kota/kabupaten yang digerakkan oleh data (city data-driven) sehingga dapat diambil keputusan dan kebijakan yang tepat berdasarkan data masa lalu, masa kini, dan prediksi pada masa mendatang.

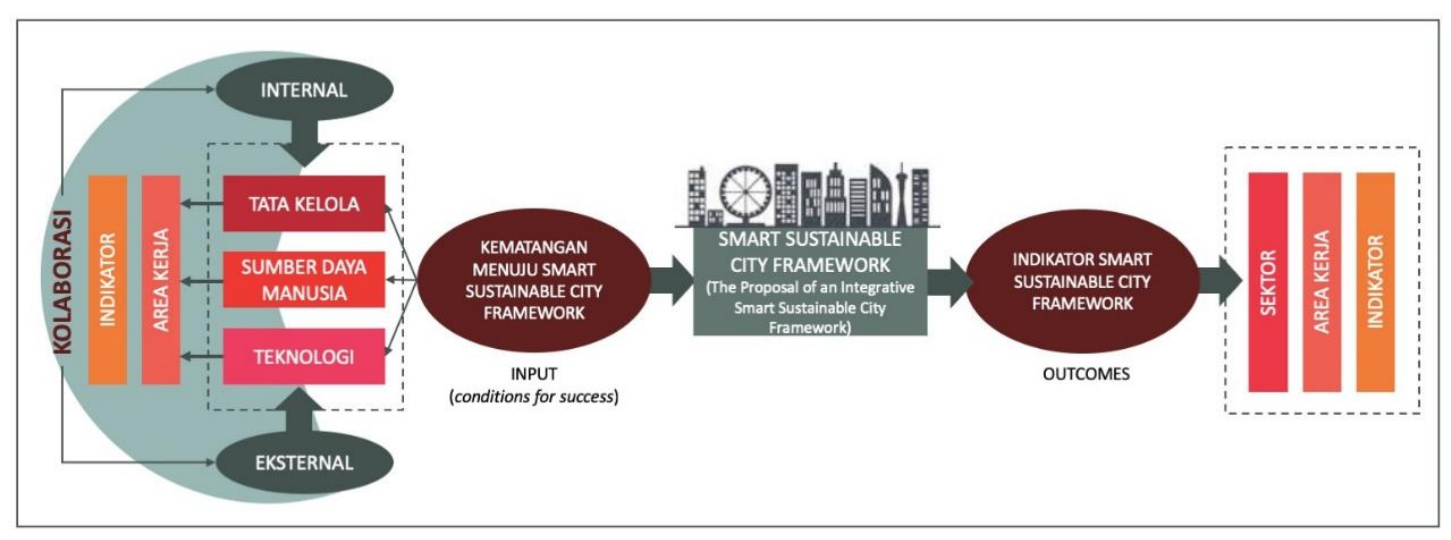

Gambar 1. Kerangka Kerja Smart Sustainable City Framework

SSCF adalah kerangka kerja integratif yang meliputi Model Smart City, Model Pengukuran Tingkat Kematangan Smart City, Model Identifikasi Prioritas Smart City, dan Model Pengukuran Ketersediaan dan Ketercapaian Indikator Smart City seperti yang terlihat pada Gambar 1. Dengan kerangka kerja ini, pemerintah daerah dapat menetapkan rencana strategis smart city berdasarkan tingkat kematangannya, prioritas dimensinya, dan ketersediaan data indikatornya. Tingkat kematangan dan prioritas dimensi diidentifikasikan sebagai titik input atau kondisi untuk sukses (condition of success) bagi daerah dalam mencapai outcome pada dimensi dan indikator smart city. Kerangka kerja ini kemudian diturunkan dalam bentuk kompleks yang meliputi 3 (tiga) lapisan, yaitu komponen smart city, dimensi smart city, dan indikator smart city. Kerangka kerja secara integratif dapat dilihat pada. Komponen smart city merupakan bagian inti yang menjadi pendorong sebuah daerah untuk mengimplementasikan smart city.

Pengukuran tingkat kematangan dilakukan pada komponen ini. Pencapaian outcome smart city sangat ditentukan oleh bagaimana daerah mendayagunakan komponennya. 


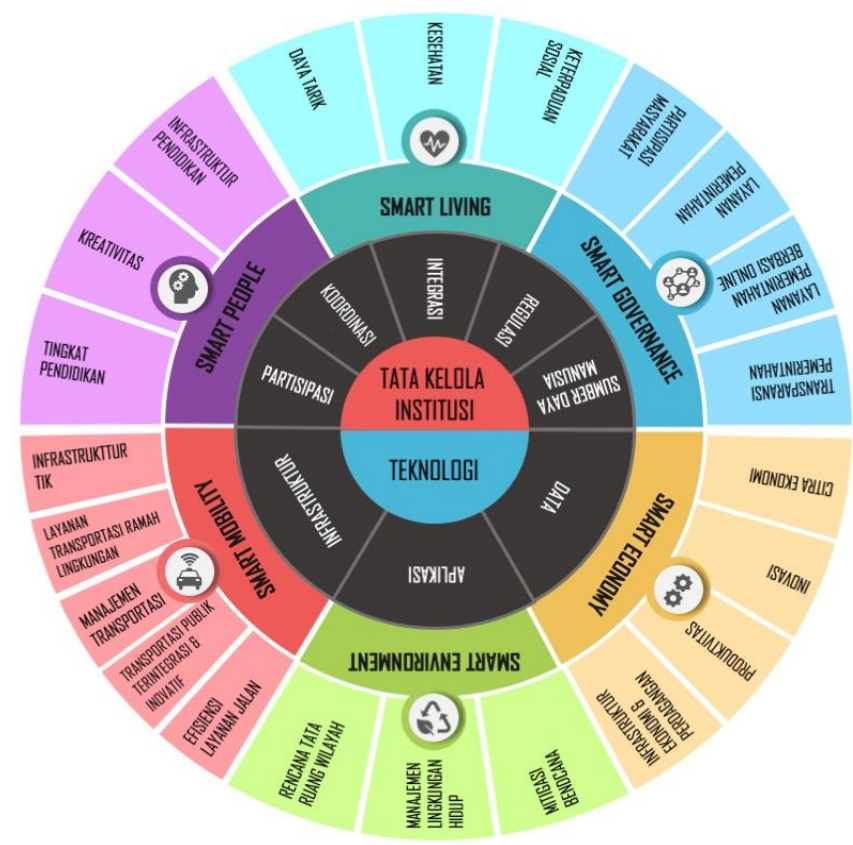

Gambar 2. Smart Sustainable City Framework

Komponen Smart Sustainable City Framework

Komponen smart city meliputi komponen tata kelola institusi dan komponen teknologi. Kerangka kerja ini ditujukan bagi pemerintah daerah untuk mengukur dirinya sendiri sehingga komponen sumber daya manusia yang melibatkan masyarakat secara umum tidak dimasukkan di dalam komponen ini. Sumber daya manusia yang melibatkan masyarakat secara umum dimasukkan dalam dimensi dan area kerja smart city tersendiri. Dalam komponen ini, sumber daya manusia yang dimaksud adalah penggerak di tata kelola institusi atau pemerintahan.

Komponen tata kelola institusi merupakan arsitektur pemerintahan yang merefleksikan standardisasi dan integrasi model operasional institusi. Tata kelola meliputi seluruh bagian tata kelola pemerintahan dan kebijakan yang fokus pada inisiatif kebutuhan. Komponen tata kelola merupakan arsitektur kebijakan untuk mengarahkan, mengatur, mengevaluasi, dan memantau terwujudnya smart city yang melibatkan kolaborasi setiap entitas kota dan kabupaten.

Kebijakan tata kelola institusi merupakan pola kepemimpinan yang mampu merangkul untuk menciptakan partisipasi dan kolaborasi serta koordinasi dan integrasi, baik dalam relasi kerja eksternal maupun internal. Seperti diungkapkan oleh Nam \& Pardo (2011a, 2011b) dan Chourabi et al, (2012), partisipasi dan kolaborasi adalah hal mutlak dalam implementasi smart city. Jika kondisi ini dapat dicapai, maka kota/kabupaten akan berada pada status Smart City 3.0 menurut Cohen (2015a, 2015b) dan pada tingkat kematangan yang optimised menurut Urban Tide (2014).

Berdasarkan peninjauan model smart city pada tingkat komponen tata kelola institusi, komponen enabler tata kelola institusi SSCF mencakup 5 (lima) area kerja dan 11 (sebelas) indikator seperti tampak pada Tabel 2. Kelima area kerja tersebut meliputi: 1) partisipasi dan produksi bersama; 
koordinasi dan integrasi; 3) integrasi dalam sumber daya manusia. pelayanan; 4) kebijakan dan rregulasi; dan 5)

Tabel 2. Area Kerja dan Indikator Komponen Tata Kelola Institusi

\begin{tabular}{|c|c|}
\hline AREA KERJA & INDIKATOR \\
\hline Partisipasi dan produksi bersama & $\begin{array}{l}\text { Pelibatan stakeholder sebagai usaha membangun kemitraan dengan } \\
\text { industri, akademisi, dan masyarakat }\end{array}$ \\
\hline Koordinasi dan integrasi & Koordinasi dan kolaborasi yang baik antar-OPD \\
\hline \multirow[t]{3}{*}{ Integrasi dalam pelayanan } & $\begin{array}{l}\text { OPD teknis bidang komunikasi dan informatika memiliki } \\
\text { kewenangan dalam pembangunan infrastruktur jaringan TIK di } \\
\text { kota/kabupaten dan OPD lain wajib berkoordinasi dengannya }\end{array}$ \\
\hline & $\begin{array}{l}\text { OPD teknis bidang komunikasi dan informatika memiliki } \\
\text { kewenangan dalam pembangunan aplikasi/sistem informasi di } \\
\text { kota/kabupaten dan OPD lain wajib berkoordinasi dengannya }\end{array}$ \\
\hline & Aplikasi/sistem informasi antar-OPD telah terintegrasi \\
\hline \multirow[t]{4}{*}{ Kebijakan dan regulasi } & $\begin{array}{l}\text { Kota/kabupaten telah memiliki organisasi formal untuk menuju } \\
\text { smart sustainable city atau smart city }\end{array}$ \\
\hline & $\begin{array}{l}\text { Kota/kabupaten telah memiliki perencanaan masterplan menuju } \\
\text { smart sustainable city atau smart city secara formal }\end{array}$ \\
\hline & $\begin{array}{l}\text { Kota/kabupaten memiliki kebijakan formal menuju smart } \\
\text { sustainable city atau smart city }\end{array}$ \\
\hline & $\begin{array}{l}\text { Kota/kabupaten telah mengalokasikan anggaran menuju smart } \\
\text { sustainable city atau smart city per tahunnya }\end{array}$ \\
\hline \multirow[t]{2}{*}{ Sumber daya manusia } & $\begin{array}{l}\text { SDM di pemerintah kota/kabupaten telah sesuai dengan kebutuhan } \\
\text { menuju smart sustainable city, khususnya kompetensi bidang TIK }\end{array}$ \\
\hline & $\begin{array}{l}\text { Terdapat workshop/bimtek/pelatihan rutin mengenai pengembangan } \\
\text { dan implementasi smart sustainable city }\end{array}$ \\
\hline
\end{tabular}

Komponen enabler teknologi merupakan infrastruktur yang berfungsi penting tetapi tidak cukup untuk menjadikan sebuah kota sebagai smart city. Teknologi merupakan sebuah mekanisme untuk merubah dan menaikkan nilai guna perangkat teknologi yang mampu meningkatkan layanan dan menciptakan kondisi pemanfaatan perangkat yang lebih baik dalam pengelolaan kota (Nam \& Pardo, 2011b). TIK tersebut meliputi infrastruktur fisik, aplikasi, dan layanan yang terintegrasi dengan data real time, terhubung dengan serangkaian proyek pembangunan yang menawarkan sejumlah potensi pengembangan manajemen dan fungsi kota (Chourabi et al., 2012). Kunci dari komponen teknologi adalah aksesibilitas, ketersediaan, terintegrasi dan mendukung interoperabilitas, berbasis layanan bergerak (mobile application), penggunaan yang berorientasi pada keluaran, serta menjamin kerahasiaan dan keamanan (Chourabi et al., 2012; Gil-Garcia et al., 2015; Nam \& Pardo, 2011a; Yudatama, n.d.).

Komponen teknologi pada SSCF meliputi seluruh infrastruktur fisik dan infrastruktur lunak yang terhubung dalam mekanisme pengelolaan kota dan kabupaten yang terintegrasi, memenuhi interoperabilitas dan kompatibilitas. Pengembangan teknologi berorientasi pada layanan pemerintah berbasis internet yang memastikan terjaminnya aksesibilitas, ketersediaan, integrasi, respons real time untuk menumbuhkkan kepedulian 
bagi tindakan prediktif, pencegahan, dan pengambilan keputusan. Terdapat 2 (dua) area kerja dalam komponen enabler teknologi, yaitu infrastruktur dan aplikasi. Aplikasi melibatkan penggunaan data untuk seluruh aktivitas berbagi pakai demi mendukung integrasi layanan pemerintah. Indikator pada kedua area kerja di komponen teknologi dapat dilihat pada

Tabel 3.

Tabel 3. Area Kerja dan Indikator Komponen Teknologi

\begin{tabular}{|c|c|}
\hline AREA KERJA & INDIKATOR \\
\hline \multirow[t]{7}{*}{ Infrastruktur } & Tersedia hotspot/WIFi untuk publik \\
\hline & Tersedia cakupan jaringan internet hingga tingkat unit Satker terbawah \\
\hline & Tersedia cakupan jaringan fiber optic hingga tingkat unit Satker terbawah \\
\hline & $\begin{array}{l}\text { Tersedia komponen infrastruktur dengan sensor terpasang (sensor, RFID, GPS, } \\
\text { CCTV, lainnya) }\end{array}$ \\
\hline & Tersedia data center \\
\hline & Terpasang dan/atau tersedia prosedur keamanan jaringan \\
\hline & $\begin{array}{l}\text { Jaringan/sensor yang terpasang terintegrasi dengan OPD lain dalam satu pusat } \\
\text { operasi tunggal dengan data real time }\end{array}$ \\
\hline \multirow[t]{12}{*}{ Aplikasi } & $\begin{array}{l}\text { Aplikasi membutuhkan otentifikasi pengguna untuk masuk ke dalam sistem } \\
\text { (perlu login) }\end{array}$ \\
\hline & Aplikasi dapat diakses oleh publik (masyarakat) \\
\hline & Aplikasi dapat diakses secara online (melalui website) \\
\hline & Aplikasi dapat diakses melalui aplikasi bergerak (mobile application) \\
\hline & $\begin{array}{l}\text { Aplikasi mendukung API (memungkinkan adanya proses data berbagi pakai } \\
\text { atau open data sharing) }\end{array}$ \\
\hline & Aplikasi terintegrasi dengan aplikasi dan/atau data terbuka lainnya \\
\hline & $\begin{array}{l}\text { Aplikasi layanan yang terintegrasi dalam pusat operasi tunggal menggunakan } \\
\text { data real time }\end{array}$ \\
\hline & Aplikasi terhubung dengan cloud computing atau data center \\
\hline & Aplikasi menggunakan layanan GIS (Geographic Information System) \\
\hline & $\begin{array}{l}\text { Aplikasi dapat mengumpulkan data dari sensor yang terpasang (sensor, RFID, } \\
\text { GPS, CCTV, dll) }\end{array}$ \\
\hline & Aplikasi dapat mengumpulkan data dari aplikasi/call center/media sosial/berita \\
\hline & $\begin{array}{l}\text { Aplikasi memberi manfaat bagi masyarakat dalam pembayaran secara } \\
\text { elektronik }\end{array}$ \\
\hline
\end{tabular}

\section{Dimensi dan Indikator Smart Sustainable City Framework}

Dimensi SSCF merupakan suatu keluaran (outcome) yang akan dicapai oleh kota/kabupaten secara berkelanjutan dengan menetapkan periode pencapaian tertentu. Dimensi SSCF meliputi6 (enam) dimensi yang terbagi ke dalam 22 area kerja, 49 indikator, dan 185 subindikator. Tabel 4 adalah cakupan dimensi, area kerja, dan subindikator pada SSCF. Identifikasi area kerja, indikator, dan subindikator mengacu pada model smart city untuk level dimensi dan indikator. Identifikasi dan penyesuaian dengan performa pemerintah daerah juga dilakukan pada perumusan dimensi dan indikator untuk memastikan outcome dapat dipenuhi oleh pemerintah daerah tanpa kendala berarti. Kesesuaian dengan SDGs, RPJMN, dan RPJMD menjadi prioritas. Beberapa indikator tidak dapat diadopsi untuk saat ini karena perilaku pemerintahan, masyarakat, dan kematangan infrastrukturnya. Namun, sesuai dengan konsep 
keberlanjutan, pengembangan indikator perlu bukanlah tujuan melainkan perjalanan.

terus dilakukan karena menjadi smart city

Tabel 4. Dimensi, Area Kerja, Subindikator dan Indikator pada Smart Sustainable City Framework

\begin{tabular}{|c|c|c|c|}
\hline Dimensi & Area Kerja & Subindikator & $\begin{array}{l}\text { Jumlah } \\
\text { Indikator }\end{array}$ \\
\hline \multirow{14}{*}{ Smart Mobility } & \multirow{3}{*}{ Efisiensi Layanan Jalan } & Cakupan dan Layanan Parkir & 2 \\
\hline & & Kualitas dan Efisiensi Layanan Jalan & 4 \\
\hline & & Cakupan dan Layanan Trotoar & 3 \\
\hline & \multirow{2}{*}{$\begin{array}{l}\text { Transportasi Publik } \\
\text { Terintegrasi dan Inovatif }\end{array}$} & Layanan Transportasi Publik & 2 \\
\hline & & Akses Multimoda & 3 \\
\hline & \multirow{4}{*}{$\begin{array}{l}\text { Layanan Transportasi } \\
\text { Ramah Lingkungan }\end{array}$} & Lalu Lintas Kendaraan Nonmotor & 2 \\
\hline & & Adopsi Kendaraan Hemat Energi & 1 \\
\hline & & Tingkat Emisi Kendaraan Bermotor & 1 \\
\hline & & $\begin{array}{l}\text { Infrastruktur Layanan } \\
\text { Ramah Lingkungan }\end{array}$ & 2 \\
\hline & \multirow[t]{3}{*}{ Manajemen Transportasi } & Pantauan Lalu Lintas & 2 \\
\hline & & Tingkat Kecelakaan Lalu Lintas & 4 \\
\hline & & $\begin{array}{lll}\text { Infrastruktur Informasi } & \text { Angkutan } \\
\text { Publik } & & \\
\end{array}$ & 2 \\
\hline & \multirow[t]{2}{*}{ Infrastruktur TIK } & Penetrasi Infrastruktur TIK & 6 \\
\hline & & Layanan TIK untuk Publik & 1 \\
\hline \multirow{4}{*}{$\begin{array}{l}\text { Smart } \\
\text { Governance }\end{array}$} & Layanan Pemerintahan & Layanan Pemerintahan & 6 \\
\hline & $\begin{array}{l}\text { Layanan Pemerintahan } \\
\text { Berbasis Online }\end{array}$ & $\begin{array}{l}\text { Layanan } \\
\text { Online }\end{array}$ & 3 \\
\hline & Transparansi Pemerintahan & Transparansi Pemerintahan & 2 \\
\hline & Partisipasi Masyarakat & Partisipasi Masyarakat & 5 \\
\hline \multirow{9}{*}{$\begin{array}{l}\text { Smart } \\
\text { Environment }\end{array}$} & \multirow{3}{*}{$\begin{array}{l}\text { Rencana Tata Ruang } \\
\text { Wilayah }\end{array}$} & Cakupan Ruang Terbuka Hijau & 5 \\
\hline & & Cakupan Ruang Publik & 3 \\
\hline & & Manajemen Tata Ruang Wilayah & 1 \\
\hline & \multirow[t]{2}{*}{ Mitigasi Bencana } & Risiko Akibat Bencana Alam & 5 \\
\hline & & Manajemen Mitigasi Bencana & 4 \\
\hline & \multirow{4}{*}{$\begin{array}{l}\text { Manajemen Lingkungan } \\
\text { Hidup }\end{array}$} & Kualitas Lingkungan Hidup & 7 \\
\hline & & Pengelolaan Sampah & 4 \\
\hline & & Sanitasi Lingkungan & 3 \\
\hline & & Konsumsi Energi & 7 \\
\hline \multirow[t]{12}{*}{ Smart Living } & \multirow[t]{3}{*}{ Daya Tarik Wisata Kota } & $\begin{array}{l}\text { Ketersediaan Layanan } \\
\text { Budaya/Amusement }\end{array}$ & 4 \\
\hline & & Tingkat Kunjungan & 3 \\
\hline & & Tata Kelola Daya Tarik Kota & 1 \\
\hline & \multirow[t]{4}{*}{ Kesehatan } & Tingkat Harapan Hidup & 3 \\
\hline & & Kesehatan Ibu Hamil dan Anak & 7 \\
\hline & & Penyakit Menahun dan Nonmenahun & 5 \\
\hline & & Infrastruktur Kesehatan & 6 \\
\hline & \multirow[t]{5}{*}{ Keterpaduan Sosial } & Tingkat Kemiskinan & 5 \\
\hline & & Persamaan Hidup terhadap Disabilitas & 2 \\
\hline & & Infrastruktur Perumahan & 4 \\
\hline & & Perlindungan Anak & 3 \\
\hline & & Tingkat Kriminalitas & 5 \\
\hline
\end{tabular}




\begin{tabular}{|c|c|c|c|}
\hline \multirow[t]{3}{*}{ Smart People } & Infrastruktur Pendidikan & Infrastruktur Pendidikan & 7 \\
\hline & Tingkat Pendidikan & Tingkat Pendidikan & 7 \\
\hline & Kreativitas & Kreativitas & 2 \\
\hline \multirow[t]{7}{*}{ Smart Economy } & \multirow[t]{2}{*}{ Inovasi } & Inovasi & 2 \\
\hline & & Kewirausahaan & 3 \\
\hline & \multirow[t]{2}{*}{ Citra Ekonomi } & Citra Kota (City Branding) & 4 \\
\hline & & Citra Ekonomi & 3 \\
\hline & \multirow[t]{2}{*}{ Produktivitas } & Produktivitas & 7 \\
\hline & & Tren Tenaga Kerja & 3 \\
\hline & $\begin{array}{l}\text { Infrastruktur Ekonomi dan } \\
\text { Perdagangan }\end{array}$ & $\begin{array}{l}\text { Infrastruktur Ekonomi dan } \\
\text { Perdagangan }\end{array}$ & 9 \\
\hline
\end{tabular}

Keenam dimensi dalam SSCF yaitu smart people, smart living, smart environment, smart mobility, smart governance, dan smart economy. Dari keenam kota dan kabupaten yang ditinjau, terdapat persamaan signifikan terkait capaian pada sisi output. Kota dan kabupaten belum memiliki target capaian pada keenam dimensi smart city dan cenderung fokus pada pembangunan infrastruktur TIK. Hal ini ditunjukkan dengan minimnya ketersediaan data indikator smart city serta perencanaan target dan sasaran yang tidak terprogram.

Smart mobility adalah kondisi kota dan kabupaten yang mampu menyediakan layanan mobilitas, baik fisik maupun nonfisik yang inovatif, terintegrasi, ramah lingkungan, aman dan nyaman, serta terkelola dengan efektif dan efisien. Manajemen mobilitas perlu direncanakan, dikendalikan, dan dipantau oleh kota dan kabupaten untuk memastikan setiap warganya terhubung mobilisasinya sehingga membuka dan meningkatkan peluang untuk kehidupan yang berkualitas, baik secara ekonomi maupun sosial. Upaya ini dicapai dengan memperhatikan 5 (lima) aspek area kerja, yaitu: 1) efisiensi layanan jalan, 2) transportasi publik terintegrasi dan inovatif, 3) layanan transportasi ramah lingkungan, 4) manajemen transportasi, dan 5) infrastruktur TIK.
Smart governance menunjukkan keadaan ketika pemerintah dapat memberikan layanan pemerintahan dengan dukungan sumber daya teknologi yang memastikan terciptanya transparansi, akuntabilitas, informatif, dan partisipasi. Smart governance menumbuhkan inovasi layanan pemerintah yang mudah dijangkau, mudah digunakan, mudah diintegrasikan, mudah dipantau, dan mudah dievaluasi. Smart governance meliputi area kerja: 1) layanan pemerintahan, 2) layanan pemerintahan berbasis online, 3) transparansi pemerintah, dan 4) partisipasi masyarakat.

Smart environment adalah kondisi ketika kota dan kabupaten memberikan kenyamanan, sumber daya yang berkelanjutan, sehingga menghasilkan keindahan fisik maupun nonfisik bagi warganya (BPSDMP Kominfo Yogyakarta, 2018). Smart environment merupakan komitmen kota dan kabupaten untuk memastikan tersedianya sumber daya berkelanjutan dan terjaminnya pelestarian lingkungan sehingga menjadi kota dan kabupaten yang layak dan nyaman untuk dihuni, baik bagi generasi kini maupun mendatang. Upaya menuju smart environment dirumuskan dalam 3 (tiga) area kerja, yaitu: 1) rencana tata ruang wilayah, 2) mitigasi bencana, 3) manajemen lingkungan hidup. 
Smart living melambangkan kota dan kabupaten yang memberikan lingkungan tempat tinggal layak yang diukur dari harmonisasi kehidupan sosial yang inklusif serta warga yang bahagia, sehat, dan aman. Kota dan kabupaten memastikan tersedianya inovasi dan kreativitas yang menjadi daya tarik kota sebagai wahana bagi warga untuk bercengkerama dan berekreasi sehingga kebahagiaannya meningkat. Kota dan kabupaten juga memastikan adanya inovasi layanan kesehatan sehingga standar kualitas hidup warganya membaik. Smart living juga merujuk pada terpadunya kehidupan sosial warga yang inklusif dan harmonis, aman dari ancaman kejahatan dan kriminalitas. Area kerja smart living meliputi: 1) daya tarik kota, 2) kesehatan, dan 3) keterpaduan sosial.

Smart people adalah kondisi ketika kota dan kabupaten menyediakan dan memberi peluang bagi meningkatnya kualitas pembangunan manusia melalui pendidikan formal dan nonformal serta terbukanya ruangruang kreativitas warga. Pembangunan manusia yang berkualitas akan mendorong terciptanya inovasi dan kreativitas dalam memecahkan masalah sosial, menumbuhkan interaksi sosial, dan meningkatkan rasa tanggung jawab publik. Area kerja smart people meliputi: 1) infrastruktur pendidikan, 2) tingkat pendidikan, dan 3) kreativitas.

Sistem ekonomi yang inovatif, produktif, berdaya saing, dengan infrastruktur ekonomi dan perdagangan yang tangguh merupakan ciri dari kota dan kabupaten yang memiliki smart economy. Sistem ekonomi kota dan kabupaten digerakkan oleh infrastuktur perekonomian yang handal dengan sumber daya manusia yang kreatif dalam menciptakan proses bisnis baru serta berproduktivitas tinggi. Dengan demikian, kota dan kabupaten memiliki citra ekonomi yang mumpuni untuk menarik minat sumber daya bertalenta dan investasi yang menggairahkan. Langkah menuju smart economy ditempuh melalui 4 (empat) area kerja yaitu: 1) inovasi, 2) citra ekonomi, 3) produktivitas, 4) infrastruktur ekonomi dan perdagangan.

Area kerja dalam setiap dimensi di SSCF memiliki indikator-indikator. Indikator SSCF merupakan alat untuk mengevaluasi dan menilai impak implementasi smart city secara spesifik. Identifikasi dapat dilakukan sebelum atau saat pelaksanaan implementasi untuk menilai kekuatan dan kelemahan kondisi saat pengukuran yang dikorelasikan dengan tingkat kematangan komponen enabler. Rumusan indikator smart sustainable city terbagi dalam subindikator-subindikator. Subindikator ini merupakan pengukuran spesifik dari tercapainya kota cerdas berkelanjutan. Subindikator diarahkan pada parameter tangible atau dapat diukur atau memiliki nilai. Subindikator mengabaikan parameter intangible atau yang tidak dapat diukur secara langsung. Hal ini dimaksudkan agar kota dan kabupaten memiliki data spesifik yang diturunkan dari subindikator sebagai sebuah dataset untuk melakukan tata kelola kota dan kabupaten. Dataset ini akan bernilai tinggi dalam proses analisis data untuk mengetahui tren, mengukur impak, memprediksi kondisi darurat, mengidentifikasi kebutuhan jangka pendek, menengah, maupun panjang. Dataset dari indikator smart sustainable city ini tidak sekedar capaian kota dan kabupaten tetapi merupakan dashboard yang bernilai strategis.

\section{Proses Pengukuran Smart Sustainable City Framework}

Kesuksesan implementasi smart city ditinjau secara holistik pada komponen enabler smart city yang meliputi komponen 
tata kelola institusi dan komponen teknologi. Proses inisiatif diperlukan dengan mempertimbangkan kematangan pada kedua komponen untuk memastikan strategi yang ditetapkan telah sesuai antara input dan outcome. Dengan demikian, kesenjangan dapat ditekan dan arah jalan yang tertuang dalam roadmap atau masterplan tidak menyimpang terlalu jauh. Kota dan kabupaten dapat menggunakan SSCF untuk mengukur tingkat kematangan, dimensi prioritas, dan ketersediaan data yang dapat digunakan untuk mengidentifikasi kondisi saat ini, menyiapkan strategi implementasi, dan mengkaji kembali peta jalan yang telah dilaksanakan. Artinya, kerangka kerja tidak hanya digunakan di awal tetapi juga sepanjang periode implementasi smart city. Tahapan pengukuran SSCF terdiri dari:

1. Pengukuran Tingkat Kematangan Komponen Smart City

Tingkat kematangan smart city diukur dengan mengadopsi teknik analisis berdasarkan Smart City Maturity Model (SCMM) yang dirilis oleh Urban Tide (2014) dengan perubahan pada metode secara kuantitatif. SCMM melakukan pemeringkatan tingkat kematangan dalam 5 (lima) tingkat, yaitu Ad-Hoc, Opportunised, Purposeful, Operasionalised, dan Optimised. Setiap tingkat mendefinisikan karakteristik status pengelolaan kota (city management status), status smart city (smart city status), dan keluaran dari implementasi (outcomes). Kota dan kabupaten melakukan evaluasi mandiri tentang status komponen tata kelola institusi dan teknologi pada saat pengukuran. Skala pengukuran pada komponen tata kelola institusi dan teknologi berbeda, demikian pula area kerja pada komponen teknologi. Skala pengukuran mengacu pada jumlah area kerja dan indikator tiap komponen. Evaluasi mandiri di area kerja data dan aplikasi pada komponen teknologi harus memperhatikan seluruh penggunaan data dan aplikasi di pemerintah daerah. Banyak dan sedikitnya jumlah aplikasi tidak memengaruhi karena terpenuhinya kecukupan indikator adalah yang terpenting. Jadi, daerah yang memiliki banyak aplikasi belum tentu memiliki tingkat kematangan yang tinggi.

Tabel 5. Skala Pengukuran Tingkat Kematangan Tata Kelola, Infrastruktur, serta Aplikasi dan Data

\begin{tabular}{|c|c|c|c|c|c|}
\hline Tingkat Kematangan & Ad-Hoc & Opportunised & Purposeful & Operasionlised & Optimised \\
\hline $\begin{array}{l}\text { Status Pengelolaan } \\
\text { Smart City }\end{array}$ & Siloed & $\begin{array}{l}\text { System } \\
\text { Collaboration }\end{array}$ & $\begin{array}{l}\text { System } \\
\text { Integration }\end{array}$ & Managed System & $\begin{array}{l}\text { Sustainable } \\
\text { and Open } \\
\text { 'System-of- } \\
\text { System' }\end{array}$ \\
\hline \multirow[t]{2}{*}{ Tata Kelola } & $0-2,2$ & $2,2-4,4$ & $4,4-6,6$ & $6,6-8,8$ & $8,8-11$ \\
\hline & $\begin{array}{l}\text { Belum tersedia } \\
\text { roadmap/kebijakan } \\
\text { transformasi digital; } \\
\text { Investasi terbatas pada } \\
\text { area tertentu. } \\
\text { Kepemimpinan, tata } \\
\text { kelola, dan } \\
\text { penganggaran yang } \\
\text { fokus pada layanan } \\
\text { khusus dengan model } \\
\text { organisasi yang }\end{array}$ & $\begin{array}{l}\text { Kebijakan dan } \\
\text { investasi diperluas; } \\
\text { beberapa layanan dan } \\
\text { kebijakan dibagi } \\
\text { dengan pihak lain. } \\
\text { Cara baru } \\
\text { kepemimpinan dan } \\
\text { model tata kelola } \\
\text { diujikan pada banyak } \\
\text { pihak dan } \\
\text { lintasorganisasi; }\end{array}$ & $\begin{array}{l}\text { Berbagi visi, } \\
\text { strategi, dan } \\
\text { roadmap smart } \\
\text { city dengan } \\
\text { multipartner } \\
\text { lintas domain; } \\
\text { membangun } \\
\text { rencana dan } \\
\text { berbagi investasi } \\
\text { untuk menjamin } \\
\text { tercapainya }\end{array}$ & $\begin{array}{l}\text { Visi, strategi, dan } \\
\text { roadmap dijalankan di } \\
\text { seluruh kota; } \\
\text { meningkatkan keluaran } \\
\text { layanan dan } \\
\text { menetapkan fondasi } \\
\text { layanan masa depan } \\
\text { yang meningkat } \\
\\
\text { Model tata kelola } \\
\text { multipartner diperluas }\end{array}$ & $\begin{array}{l}\text { Strategi disusun } \\
\text { secara optimal } \\
\text { dan } \\
\text { dikembangkan } \\
\text { berbasis impak } \\
\text { daya saing kota; } \\
\text { investasi cerdas } \\
\text { telah terlihat } \\
\text { impaknya pada } \\
\text { prioritas strategi } \\
\text { kota. Kota }\end{array}$ \\
\hline
\end{tabular}




\begin{tabular}{|c|c|c|c|c|c|}
\hline & $\begin{array}{l}\text { terbatas/tradisional; } \\
\text { Pengelolaan } \\
\text { hubungan stakeholder } \\
\text { terpisah (klien, } \\
\text { provider, supplier, } \\
\text { pengguna). }\end{array}$ & $\begin{array}{l}\text { berbagi anggaran } \\
\text { secara akuntabel pada } \\
\text { inisiatif terpisah. } \\
\text { Internal organisasi } \\
\text { berkomitmen dalam } \\
\text { layanan digital untuk } \\
\text { memperluas } \\
\text { partisipasi warga; }\end{array}$ & $\begin{array}{l}\text { outcome yang } \\
\text { terukur. }\end{array}$ & $\begin{array}{l}\text { dan meningkatkan } \\
\text { pengambilan keputusan } \\
\text { pada outcome layanan } \\
\text { seluruh kota; pengguna } \\
\text { layanan adalah } \\
\text { influence yang kuat }\end{array}$ & $\begin{array}{l}\text { menjadi inklusif; } \\
\text { literasi digital } \\
\text { meningkat }\end{array}$ \\
\hline Infrastruktur & $\begin{array}{l}\text { Arsitektur dan } \\
\text { infrastruktur TIK } \\
\text { secara dominan } \\
\text { dirancang untuk } \\
\text { mendukung setiap lini } \\
\text { aplikasi proses bisnis. } \\
\text { Investasi pada } \\
\text { jaringan sensor ( real } \\
\text { time) untuk layanan } \\
\text { tertentu sangat } \\
\text { terbatas }\end{array}$ & $\begin{array}{l}\text { Infrastruktur TIK } \\
\text { terintegrasi telah } \\
\text { tersedia tetapi } \\
\text { digunakan untuk } \\
\text { layanan terbatas } \\
\text { (intern unit). Jaringan } \\
\text { sensor berbagi pakai } \\
\text { mulai digunakan. } \\
\text { Terdapat hambatan } \\
\text { saling memahami } \\
\text { antarpihak }\end{array}$ & $\begin{array}{l}\text { Investasi dan } \\
\text { implementasi } \\
\text { pada integrasi } \\
\text { arsitektur TIK } \\
\text { antarorganisasi } \\
\text { telah dilakukan. } \\
\text { Terjadi } \\
\text { perencanaan dan } \\
\text { penyertaan } \\
\text { investasi untuk } \\
\text { pembangunan } \\
\text { kota secara luas } \\
\text { pada aset yang } \\
\text { terhubung. }\end{array}$ & $\begin{array}{l}\text { Pembangunan } \\
\text { infrastruktur TIK } \\
\text { lintasorganisasi telah } \\
\text { ditingkatkan dan } \\
\text { disesuaikan. Arsitektur } \\
\text { memungkinkan } \\
\text { percepatan layanan } \\
\text { inovasi. Aset } \\
\text { infrastruktur yang } \\
\text { tersebar telah terhubung }\end{array}$ & $\begin{array}{l}\text { Kota secara } \\
\text { berkelanjutan } \\
\text { menelaah, } \\
\text { beradaptasi, dan } \\
\text { berinvestasi } \\
\text { dalam arsitektur } \\
\text { TIK untuk } \\
\text { mendorong } \\
\text { transformasi } \\
\text { layanan. } \\
\text { lingkungan } \\
\text { berjaringan di } \\
\text { seluruh kota }\end{array}$ \\
\hline \multirow[t]{2}{*}{ Aplikasi dan Data } & $0-2,4$ & $2,4-4,8$ & $4,8-7,2$ & $7,2-9,6$ & $9,6-12$ \\
\hline & $\begin{array}{l}\text { Data dibagi untuk } \\
\text { layanan khusus. Data } \\
\text { digunakan kembali } \\
\text { dan diintegrasikan } \\
\text { secara terbatas pada } \\
\text { sistem yang berbeda } \\
\text { untuk operasi yang } \\
\text { berbeda. Isu data yang } \\
\text { terintegrasi, } \\
\text { berkualitas, } \\
\text { terlindung, dan aman } \\
\text { menjadi wacana tetapi } \\
\text { belum } \\
\text { diimplementasikan. }\end{array}$ & $\begin{array}{l}\text { Beberapa dataset } \\
\text { dibuka untuk publik. } \\
\text { Beberapa data lanjut } \\
\text { dibagi dan dianalisis } \\
\text { dalam aplikasi. } \\
\text { Terdapat hambatan } \\
\text { untuk } \\
\text { mengoptimalisasi } \\
\text { dataset antarpihak dan } \\
\text { membutuhkan solusi } \\
\text { segera }\end{array}$ & $\begin{array}{l}\text { Strategi } \\
\text { pengelolaan dan } \\
\text { optimasi data } \\
\text { bersama telah } \\
\text { disepakati } \\
\text { antarpihak. } \\
\text { Investasi pada } \\
\text { pengelolaan data } \\
\text { tingkat lanjut, } \\
\text { menangkap, } \\
\text { menganalisis, dan } \\
\text { mengolah aplikasi } \\
\text { big data. } \\
\text { Jangkauan luas } \\
\text { pada data terbuka } \\
\text { untuk mendorong } \\
\text { inovasi lebih luas. } \\
\text { Warga berbagi } \\
\text { data sektor } \\
\text { layanan utama. }\end{array}$ & $\begin{array}{l}\text { Dataset digunakan } \\
\text { untuk memberikan } \\
\text { informasi yang dapat } \\
\text { ditindaklanjuti. } \\
\text { Tangkapan dan analisis } \\
\text { data secara luas untuk } \\
\text { mendorong peningkatan } \\
\text { pengambilan keputusan } \\
\text { dan perancangan } \\
\text { layanan. Pembangunan } \\
\text { data terbuka berbasis } \\
\text { komunitas untuk } \\
\text { menciptakan layanan } \\
\text { baru dihargai oleh } \\
\text { pengguna. Warga } \\
\text { berkeinginan } \\
\text { (berkontribusi) untuk } \\
\text { berbagi data secara luas }\end{array}$ & $\begin{array}{l}\text { Analisis data } \\
\text { digunakan secara } \\
\text { dinamis dan } \\
\text { otomatis dalam } \\
\text { memprediksi dan } \\
\text { mencegah layanan } \\
\text { dan peningkatan } \\
\text { kapabilitas } \\
\text { respons terhadap } \\
\text { aktivitas yang } \\
\text { tidak terprediksi. } \\
\text { Data terbuka yang } \\
\text { dibangkitkan } \\
\text { komunitas akan } \\
\text { membuka peluang } \\
\text { inovasi layanan } \\
\text { publik. }\end{array}$ \\
\hline
\end{tabular}

2. Pengukuran Prioritas Dimensi Smart City Pengukuran prioritas dilakukan dengan metode pengambilan keputusan dari banyak kriteria (Multi Criteria Decision Making, MCDM). Perbandingan berpasangan antardimensi smart city dan antararea kerja dalam satu dimensi dilakukan untuk mengubah nilai intangible menjadi tangible yang dapat dipercayai dan bernorma objektif. Prinsipnya adalah memberikan penilaian tentang kepentingan relative dari 2 (dua) kriteria yang ada. Tingkat prioritas dibagi dari struktur kerangka kerja smart sustainable city pada tingkat pertama dan tingkat kedua. Tingkat pertama adalah menentukan prioritas pada dimensi smart city. Dari keenam dimensi yang ada, dimensi mana yang diprioritaskan oleh pemerintah daerah. Tingkat kedua adalah menentukan prioritas pada area kerja di tiap dimensi smart city. Penilaian dilakukan sendiri oleh pemerintah daerah sehingga 
hasilnya akan berbeda antara daerah satu dengan lainnya sesuai dengan permasalahan, kebutuhan, dan kepentingannya.

3. Pengukuran Tingkat Ketersediaan Data Indikator Smart City

Identifikasi ketersediaan data merupakan cara untuk merumuskan indikator-indikator capaian smart city. Identifikasi meliputi atribut tersedia atau tidak tersedianya data, sumber data, potensi integrasi, dan nilai data. Pada konteks implementasi, identifikasi memiliki arti penting untuk menakar kesesuaian pada tingkat prioritas dan tingkat kematangan dengan capaian indikator smart city saat ini.

Perlu ditekankan bahwa konsep smart sustainable city memiliki prinsip berkelanjutan sehingga proses pencapaiannya pun berkembang dan dilakukan secara berkelanjutan.

\section{KESIMPULAN DAN SARAN}

Smart Sustainable City Framework adalah sekumpulan instrumen yang dapat digunakan oleh kota dan kabupaten untuk menyusun strategi implementasi smart city secara berkelanjutan dan komprehensif. Smart Sustainable City Framework merupakan hasil eksplorasi terhadap model smart city yang berkembang dan tinjauan terhadap kota dan kabupaten peserta Gerakan 100 Smart City. Tujuan utama dari kerangka kerja ini adalah membantu kota dan kabupaten untuk mengidentifikasi kematangan komponen smart city-nya dan menyusun strategi implementasi berdasarkan tingkat kematangan, prioritas, dan ketersediaan data indikator. Dalam konteks daya saing, SSCF dapat digunakan dengan terlebih dahulu mengukur tingkat kematangan komponen enabler smart sustainable city yang di dalamnya kota dan kabupaten tidak dapat dikelompokkan berdasarkan peringkat.
SSCF meliputi komponen enabler, dimensi, dan indikator. Komponen enabler adalah pondasi dari terlaksananya smart sustainable city yang terdiri dari komponen tata kelola institusi dan teknologi. Kekuatan pada komponen enabler akan mengidentifikasikan tingkat kematangan dan generasi pengembangan smart sustainable city. Dimensi smart sustainable city adalah sektor layanan yang harus dipenuhi oleh kota dan kabupaten untuk mewujudkan kota dan kabupaten yang berkualitas untuk ditempati. Komponen dimensi tersebut meliputi smart mobility, smart governance, smart environment, smart living, smart people, dan smart economy. Terdapat area kerja, indikator, dan subindikator dari setiap dimensi yang merujuk pada terpenuhinya indikator kenyamanan dan keberlangsungan kehidupan berkualitas bagi setiap orang.

SSCF dalam penelitian ini belum memasukkan komponen manusia dalam konteks masyarakat. Manusia dalam kerangka kerja ini adalah sumber daya manusia internal pemerintah yang termasuk dalam komponen tata kelola. Perlu dilakukan penelitian lebih lanjut tentang komponen manusia (masyarakat) serta area kerja yang ada di dalamnya. Hal ini penting dilakukan karena keberhasilan smart city ditentukan pula oleh kolaborasi antara pemerintah daerah, swasta, dan masyarakat.

\section{DAFTAR PUSTAKA}

Anand, A., Winfred Rufuss, D. D., Rajkumar, V., \& Suganthi, L. (2017). Evaluation of Sustainability Indicators in Smart Cities for India Using MCDM Approach. Energy Procedia, 141, 211-215. https://doi.org/10.1016/j.egypro.2017.11. 094

Anindra, F., Supangkat, S. H., \& Kosala, R. R. (2018). Smart Governance as Smart City Critical Success Factor (Case in 15 Cities 
in Indonesia). Proceeding - 2018

International Conference on ICT for

Smart Society: Innovation Toward Smart

Society and Society 5.0, ICISS 2018,

(October).

https://doi.org/10.1109/ICTSS.2018.8549

923

Anthopoulos, L., \& Janssen, M. (2015).

Comparing Smart Cities with Different

Modeling Approaches, 1997, 525-528.

BPSDMP Kominfo Yogyakarta. (2018).

SURVEI TINGKAT KEMATANGAN

PROVINSI JAWA TENGAH, PROVINSI

BALI DAN D.I. YOGYAKARTA

MENUJU SMART PROVINCE Kajian

Dimensi Teknologi: Infrastruktur,

Aplikasi dan Data. Yogyakarta.

BPSDMP Kominfo Yogyakarta. (2019). Smart

Sustainable City Smart Sustainable City Model.

Chourabi, H., Nam, T., Walker, S., Gil-Garcia,

J. R., Mellouli, S., Nahon, K., ... Scholl,

H. J. (2012). Understanding smart cities:

An integrative framework. Proceedings

of the Annual Hawaii International

Conference on System Sciences, (June 2015), 2289-2297. https://doi.org/10.1109/HICSS.2012.615

Citiasia Center for Smart Nation. (2016). Smart

Nation: Mastering Nation , s

Advancement from Smart Readiness to Smart City.

Cohen, B. (2015a). The Evolution of The Evolution of Desire. Diambil dari https://www.fastcompany.com/3047795/t he-3-generations-of-smart-cities

Cohen, B. (2015b). The Smartest Cities In The

World 2015: Methodology. Fast Company. Diambil dari http://www.fastcoexist.com/3038818/thesmartest-cities-in-the-world-2015methodology
Giffinger, R. (2007). Smart cities Ranking of European medium-sized cities. October, 16(October), 13-18. https://doi.org/10.1016/S02642751(98)00050-X

Giffinger, R., \& Gudrun, H. (2010). Smart CIties Ranking: An Effective Instrument For The Positioning Of Cities. ACE: Architecture, City, and Environment, 4(12), 7-25.

Gil-Garcia, J. R., Pardo, T. A., \& Nam, T. (2015). What makes a city smart? Identifying core components and proposing an integrative and comprehensive conceptualization. Information Polity, 20(1), 61-87. https://doi.org/10.3233/IP-150354

Hara, M., Nagao, T., Hannoe, S., \& Nakamura, J. (2016). New key performance indicators for a smart sustainable city. Sustainability (Switzerland), 8(3). https://doi.org/10.3390/su8030206

ISO/IEC. (2014). Information technology Smart cities. Smart cities - Preliminary Report 2014, 1-71.

Lazaroiu, G. C., \& Roscia, M. (2012). Definition methodology for the smart cities model. Energy, 47(1), 326-332. https://doi.org/10.1016/j.energy.2012.09. 028

Mudjiyanto, B. (2018). Tipe Penelitian Eksploratif Komunikasi. Jurnal Studi Komunikasi dan Media, 22(1), 65. https://doi.org/10.31445/jskm.2018.2201 05

Nam, T., \& Pardo, T. A. (2011a). Conceptualizing smart city with dimensions of technology, people, and institutions. Proceedings of the 12th Annual International Digital Government Research Conference on Digital Government Innovation in Challenging 
Times - dg.o '11, 282. https://doi.org/10.1145/2037556.2037602

Nam, T., \& Pardo, T. A. (2011b). Smart city as urban innovation: focusing on management, policy, and context. In ICEGOV '11 Proceedings of the 5th International Conference on Theory and Practice of Electronic Governance (hal. 185-194).

https://doi.org/10.1145/2072069.2072100

Purnomo, F., \& Prabowo, H. (2016). Smart city indicators: A systematic literature review. Journal of Telecommunication, Electronic and Computer Engineering, 8(3), 161-164.

Smith, J., \& Firth, J. (2011). Qualitative data analysis: the framework approach. Nurse researcher, 18(2), 52-62.

Supangkat, S. H., \& Arman, A. A. (2018). The Implementation of Garuda Smart City Framework for Smart City Readiness Mapping in Indonesia. Journal of AsiaPacific Studies, 32(4), 169-176.
Supangkat, S. H., Arman, A. A., Nugraha, R. A., \& Fatimah, Y. A. (2018). The Implementation of Garuda Smart City Framework for Smart City Readiness Mapping in Indonesia. Journal of AsiaPacific Studies (Waseda University) No.32, (4), 169-176.

UNECE, \& ITU. (n.d.). The UNECE-ITU Smart Sustainable Cities Indicators.pdf.

Urban Tide. (2014). Smart Cities Maturity Model and Self-Assessment Tool. Diambil dari https://www.scottishcities.org.uk/site/ass ets/files/1103/smart_cities_readiness_ass essment_-_guidance_note.pdf

Yudatama, U. (n.d.). Pengukuran penerapan teknologi informasi untuk membangun smart city. In Konferensi Nasional Sistem Informasi (KNSI). 